\title{
WILEY-VCH
}

DOI: 10.1002/ ((please add manuscript number))

Article type: Full Paper

\section{Ammonium vanadium bronze as potassium ion battery cathode with high rate capability and cyclability}

Yang Xu, Huishuang Dong, Min Zhou, Chenglin Zhang, Yuhan Wu, Wei Li, Yulian Dong, and Yong Lei ${ }^{*}$

Dr. Y. Xu, Dr. M. Zhou, C. L. Zhang, Y. H. Wu, Prof. Y. Lei

Institute of Physics and IMN MacroNano, Ilmenau University of Technology, Ilmenau 98693, Germany

E-mail: yong.lei@tu-ilmenau.de

H. S. Dong, W. Li, Y. L. Dong

Institute of Nanochemistry and Nanobiology, School of Environmental and Chemical

Engineering, Shanghai University, Shanghai 200444, China

Keywords: vanadium bronze, layered structure, cathode, potassium ion batteries

\begin{abstract}
K-ion batteries (KIBs) are a promising alternative to lithium-ion batteries. Despite the rapid development of KIB anodes, cathodes have not developed to the same extent due to the sluggish kinetics of $\mathrm{K}$-ion intercalation. Here, ammonium vanadium bronze $\mathrm{NH}_{4} \mathrm{~V}_{4} \mathrm{O}_{10}$ (NVO) is proposed as a potential KIB cathode material. The as-synthesized NVO features a large interlayer spacing of $9.8 \AA$ and self-assembled flower-like architecture. The cathode delivers a high capacity of $136 \mathrm{mAh} \mathrm{g}^{-1}\left(50 \mathrm{~mA} \mathrm{~g}^{-1}\right)$ and a decay rate of $0.02 \%$ per cycle over 200 cycles in the range of $1-3.8 \mathrm{~V}$. It retains $94 \%$ capacity $\left(80 \mathrm{mAh} \mathrm{g}^{-1}\right)$ after 200 cycles in the range of 2-3.8 V. Moreover, it exhibits fast rate capability by delivering $51 \mathrm{mAh} \mathrm{g}^{-1}$ at a rate as high as $3 \mathrm{~A} \mathrm{~g}^{-1}(2-3.8 \mathrm{~V})$, being $90 \%$ of the capacity at $0.1 \mathrm{~A} \mathrm{~g}^{-1}$. Electrochemical mechanism study suggests that $\mathrm{K}$-ion storage in $\mathrm{NVO}$ is a topotactic process, where transition between $\mathrm{V}^{4+}$ and $\mathrm{V}^{5+}$ occurs. It also shows prevention of deammoniation at a higher voltage towards $4.2 \mathrm{~V}$ is critical for the structural stability of NVO. This work may stimulate future exploitation of vanadium oxides in KIBs and more insights into mechanisms of $\mathrm{K}$-ion storage.
\end{abstract}




\section{WILEY-VCH}

\section{Introduction}

The greater abundance of $\mathrm{K}$ in the earth's crust comparing with $\mathrm{Li}(1.5 \mathrm{vs} .0 .0017$, mass $\%)$ has prompted researchers to investigate the feasibility of $\mathrm{K}$-ion batteries (KIBs). ${ }^{[1,2]}$ One important advantage of KIBs is that $\mathrm{K}$ even has a lower standard redox potential than $\mathrm{Li}$ in non-aqueous electrolytes, which can be translated into a potentially higher cell voltage of KIBs comparing with that of Li-ion batteries (LIBs). ${ }^{[1,3]}$ Another important advantage is that $\mathrm{K}$ electrolytes exhibit higher conductivity than $\mathrm{Li}$ electrolytes, which is attributed to the smaller Stokes radius of solvated K-ions because of their weak Lewis acidity and the lower interfacial reaction resistance deriving from the smaller desolvation activation energy. ${ }^{[1,4]}$ Regarding the mass concerns of using heavier $\mathrm{K}$-ions to replace Li-ion as charge carriers, it is only fair to compare the formula weight of electrode materials to consider their gravimetric capacity, rather than considering the weight of the alkali-metals, because $\mathrm{K}$ metal would not be used. ${ }^{[2,3]}$ So the use of K may not significantly affect the total mass of the cell. Given these advantages and considerations, KIBs have attracted rapidly growing interest, and many materials have been evaluated as potential electrodes.

Anodes of KIBs have developed quickly over the past few years, owing to various types of mechanisms to electrochemically store K-ions, such as intercalation, alloying, conversion and their combinations. Impressive performance has been achieved among many materials, including carbons, ${ }^{[5-7]}$ metals $^{[8,9]}$ and metal chalcogenides/phosphides. ${ }^{[10-12]}$ However, cathodes of KIBs have not developed to the same extent as anodes. The mechanism of storing $\mathrm{K}$-ions in cathodes is limited to intercalation, for which the large size of $\mathrm{K}^{+}$imposes large diffusion resistance, often resulting in sluggish kinetics. Utilizing prominent structural features of materials therefore is extremely critical to accommodate the large sized $\mathrm{K}^{+}$and improve the kinetics. Prussian blue analogues (PBAs) have been reported as potential KIB cathodes because their framework structures have open channels and large interstitial sites, which enables rapid K-ion diffusion. But the low conductivity and poor cycling stability limit 


\section{WILEY-VCH}

their K-ion storage performance. ${ }^{[13-15]}$ Polyanion compounds are another type of KIB cathodes with open framework structures, but they fail to show competitive capacities at high rates (typically less than $\left.0.8 \mathrm{~A} \mathrm{~g} \mathrm{~g}^{-1}\right){ }^{[16-18]}$ This calls for a continuing exploration of structural features that endow materials with long-term cycling stability and high rate capability.

Layered metal oxides have appealing structures where the space between the metal-oxide layers naturally forms two-dimensional diffusion pathways for ion (de)intercalation. Currently, research of layered metal oxides is very few in KIBs, presumably due to the larger size of $\mathrm{K}^{+}$ than $\mathrm{Li}^{+}$and $\mathrm{Na}^{+}$. P2- and P3-type $\mathrm{K}_{x} \mathrm{MO}_{2}(\mathrm{M}=\mathrm{Mn}, \mathrm{Co}, \mathrm{Cr})$, as the equivalents in LIBs, has been reported as potential candidates for K-ion storage. ${ }^{[19-21]}$ These compounds exhibit low reversible capacities $\left(50-70 \mathrm{mAh} \mathrm{g}^{-1}\right)$ even at very low rates $\left(\leq 30 \mathrm{~mA} \mathrm{~g}^{-1}\right)$, and their rate capability is still limited to $\sim 1 \mathrm{~A} \mathrm{~g}^{-1}$. It should be noted that the large volume change and layer gliding upon K-extraction might cause structural changes, which could prevent full $\mathrm{K}$ reinsertion upon discharge and seriously limit reversible cycles. ${ }^{[1,21,22]}$ Recently, Wang et al. reported a layered polyoxometalate $\mathrm{K}_{0.7} \mathrm{Fe}_{0.5} \mathrm{Mn}_{0.5} \mathrm{O}_{2}$ that shows a high initial capacity of 178 $\mathrm{mAh} \mathrm{g}^{-1}$ at $20 \mathrm{~mA} \mathrm{~g}^{-1}$, but the capacity quickly decreases by $30 \%$ only after 45 cycles. $^{\text {[23] }}$ Vanadium oxides represent another typically layered metal oxides and have been known as highly reactive materials with a diverse and rich intercalation chemistry. ${ }^{[24-26]}$ The layered structure and redox intercalation ability allow insertion of various intercalant species. Perhaps one of the most fascinating features of layered vanadium oxides involves a process in which the layers become partially reduced and the interlayer spacing becomes expanded upon the insertion of cationic species, resulting in the formation of vanadium bronzes. Surprisingly, the use of vanadium bronzes in KIBs was reported just recently. For instance, Clites et al. reported $\mathrm{K}_{0.42} \mathrm{~V}_{2} \mathrm{O}_{5} \cdot 0.25 \mathrm{H}_{2} \mathrm{O}$ with expanded interlayer spacing of $9.65 \AA$. Although the potassium vanadium bronze exhibits a high initial capacity at a low rate of $20 \mathrm{~mA} \mathrm{~g}^{-1}$, but the capacity quickly drops to $74 \%$ after 50 cycles and only $58 \%$ is retained at an increased rate of $0.3 \mathrm{~A} \mathrm{~g} \mathrm{~g}^{-1} \cdot{ }^{[27]} \mathrm{K}_{0.5} \mathrm{~V}_{2} \mathrm{O}_{5}$ exhibits moderate cycling stability of retaining $83 \%$ capacity after 80 


\section{WILEY-VCH}

cycles at $20 \mathrm{~mA} \mathrm{~g}^{-1}$, but its rate capability is far from satisfaction $\left(45 \mathrm{mAh} \mathrm{g}^{-1}\right.$ at $\left.0.2 \mathrm{~A} \mathrm{~g}^{-1}\right){ }^{[28]}$ Therefore, there exists immediate need to explore vanadium bronzes in order to take full advantages of their structural diversity and rich intercalation chemistry.

In this work, we investigate ammonium vanadium bronze $\mathrm{NH}_{4} \mathrm{~V}_{4} \mathrm{O}_{10}(\mathrm{NVO})$ as a potential KIB cathode for the first time. The crystal structure of NVO (inset in Figure 1b) is an assembly of double layers made up of distorted octahedra and trigonal bipyramids of V-O polyhedral stacking along the $c$-axis of the unit cell and encapsulating ammonium ions. The as-synthesized NVO features a large interlayer spacing of $9.8 \AA$ and self-assembled flowerlike architecture, which benefits K-ion diffusion and structural stabilization for enduring prolonged electrochemical cycles. We studied the K-ion storage mechanism in NVO in a voltage window of 1-4.2 V, and our study shows that the instability of the layered structure is caused by the deammoniation from the interlayer space and the trapping of $\mathrm{K}^{+}$in the interlayer space. Based on the study, we conducted a refinement of K-ion storage performance by controlling voltage window. NVO delivers a high capacity of $136 \mathrm{mAh} \mathrm{g}^{-1}$ at $50 \mathrm{~mA} \mathrm{~g}^{-1}$ and a low capacity decay rate of $0.02 \%$ per cycle over 200 cycles in the window of 1-3.8 V. It also retains $94 \%$ capacity $\left(80 \mathrm{mAh} \mathrm{g}^{-1}\right)$ after 200 cycles in the window of 2-3.8 V. Moreover, fast rate capability is demonstrated in 2-3.8 V. NVO delivers a capacity of $51 \mathrm{mAh} \mathrm{g}^{-1}$ at a rate as high as $3 \mathrm{~A} \mathrm{~g} \mathrm{~g}^{-1}$, which is $90 \%$ of the capacity at $0.1 \mathrm{~A} \mathrm{~g}^{-1}$. To the best of our knowledge, the presented cycling stability and rate capability are the best among all the vanadium oxide KIB cathodes. Given the facile synthesis and great electrochemical performance, our investigation may bring more attention to vanadium oxides in KIBs and provide insight into K-ion storage in materials with structural features.

\section{Results and discussion}

NVO was synthesized by a facile hydrothermal method in a solution where $\mathrm{V}_{2} \mathrm{O}_{5}$ was partially reduced by oxalic acid at $180^{\circ} \mathrm{C}$. Figure 1a shows the X-ray diffraction (XRD) that 


\section{WILEY-VCH}

resembles monoclinic structure. The lattice parameters were refined to be $\mathrm{a}=11.46 \AA$, $\mathrm{b}=$ $3.66 \AA, c=10.0 \AA, \alpha=\gamma=90^{\circ}$, and $\beta=89^{\circ}$, with space group of $\mathrm{C} 2 / \mathrm{m}$. No impurities such as $\mathrm{V}_{2} \mathrm{O}_{5}$ or $\mathrm{VO}_{2}$ are detected. The strong (001) peak located at $8.8^{\circ}$ indicates a large interlayer spacing of the layered structure of NVO. The large interlayer spacing is associated with the presence of $\mathrm{NH}_{4}{ }^{+}$between the adjacent $\mathrm{V}-\mathrm{O}$ layers, and this feature can well accommodate $\mathrm{K}^{+}$ and facilitate its diffusion. Thermogravimetric analysis (TGA, Figure S1) reveals the water content in NVO is 1.1 per molecule, and it decomposes into $\mathrm{V}_{2} \mathrm{O}_{5}$ at the temperature higher than $450^{\circ} \mathrm{C}$. We annealed $\mathrm{NVO}$ in air at $500^{\circ} \mathrm{C}$ for $2 \mathrm{~h}$, and the sample shows good crystallinity of orthorhombic $\mathrm{V}_{2} \mathrm{O}_{5}$ with the (001) interlayer spacing shrinking to $4.38 \AA$ (Figure S2). This indicates a phase transition from $\mathrm{NVO}$ to $\mathrm{V}_{2} \mathrm{O}_{5}$ upon the release of $\mathrm{NH}_{3}$ and $\mathrm{H}_{2} \mathrm{O}^{[29,30]}$ and proves the important role of $\mathrm{NH}_{4}{ }^{+}$to expand the distance between the V-O layers. Raman spectrum of NVO (Figure 1b) displays eight bands that are assigned to the vibrational modes of $\mathrm{V}=\mathrm{O}, \mathrm{V}-\mathrm{O}$ and $\mathrm{V}-\mathrm{O}-\mathrm{V}$ in the wave number range of $100-1200 \mathrm{~cm}^{-1}$, which agrees with previous reports. ${ }^{[31,32]}$ Figure 1c shows Fourier transform infrared (FTIR) spectrum of NVO, where distinguish vibrational modes of $\mathrm{V}-\mathrm{O}$ and $\mathrm{N}-\mathrm{H}$ can be observed. The bands at 525 and $756 \mathrm{~cm}^{-1}$ are assigned to the bending mode of $\mathrm{V}-\mathrm{O}$ and stretching mode of $\mathrm{V}-\mathrm{O}-\mathrm{V}$, respectively. The band at $998 \mathrm{~cm}^{-1}$ is attributed to the stretching mode of $\mathrm{V}=\mathrm{O}$ in the distorted $\mathrm{VO}_{6}$ octahedra. The bands around 1402 and $3164 \mathrm{~cm}^{-1}$ correspond to the bending and stretching modes of $\mathrm{N}-\mathrm{H}$, respectively, once again confirming the presence of $\mathrm{NH}_{4}{ }^{+} \cdot{ }^{[33]} \mathrm{In}$ addition, the bands at 1620 and $3450 \mathrm{~cm}^{-1}$ indicate the presence of $\mathrm{H}_{2} \mathrm{O}$, which is consistent with the TGA results. The X-ray photoelectron spectroscopy (XPS) survey spectrum (Figure S3) reveals NVO consists of only V, O and N, which demonstrates the purity of the sample. The V 2p core level spectrum (Figure 1d) illustrates the mixed oxidation state of V, which is typical for vanadium bronze materials. ${ }^{[34,35]}$ The peaks at $517.7 \mathrm{ad} 525.0 \mathrm{eV}$ are assigned to the $2 \mathrm{p} 5 / 2$ and $2 \mathrm{p} 3 / 2$ of $\mathrm{V}^{5+}$, while those at lower binding energies are assigned to $\mathrm{V}^{4+}$. The $\mathrm{N}$ 


\section{WILEY-VCH}

1s core level spectrum (inset in Figure 1d) provides additional support of the presence of $\mathrm{NH}_{4}^{+}$.

The morphology and structure of NVO were studied using field-emission scanning scan microscopy (FESEM) and transmission electron microscopy (TEM). Figure 2a shows NVO consists of high-yield flower-like architectures with the diameter in a range of 6-10 $\mu \mathrm{m}$. SEM (Figure 2b) and TEM images (Figure S4) of an individual "flower" illustrate that it is assembled by numerous nanowires in a radial direction. The length of the nanowires is estimated to be 3-5 $\mu \mathrm{m}$. Figure $2 \mathbf{c}$ and $\mathbf{2 d}$ show the nanowires exfoliated from the "flowers" during TEM sample preparation. The nanowires have smooth surface and a width of $\sim 100$ $\mathrm{nm}$. Detailed crystal structure of the nanowires can be seen in the HRTEM images and SAED patterns in Figure 2e and 2f. The SAED patterns reveal the single crystallinity of the nanowires even with chemically adsorbed water. As show in Figure 2e, clear lattice fringes can be observed and a spacing of $9.8 \AA$ is identified, which corresponds to the spacing of the (001) plane and demonstrates the characteristically layered structure of NVO. Another two sets of lattice fringes are observed from the same direction of electron beam and correspond to the spacing of the (110) and (111) planes (Figure 2f). This is in good agreement with the results observed in Figure 2e. To summarize the phase, morphology and structure characterizations, NVO "flowers" are successfully obtained by controlling the reaction temperature. Single crystalline nanowires assemble radially to form the "flowers", and each nanowire shows a characteristic layered structure with a large interlayer spacing of $9.8 \AA$. The assembling pattern and large interlayer spacing are expected to ensure structural integrity and facilitate K-ion diffusion simultaneously.

The KIB performance of NVO was first examined by galvanostatic charge/discharge at 50 $\mathrm{mA} \mathrm{g}^{-1}$ in the voltage range of 1-4.2 V. Figure 3a shows the profiles of the first discharge (D1), first charge (C1), and second discharge process (D2). D1 profile exhibits a voltage plateau at $2.5 \mathrm{~V}$ and a quasi-plateau centered at $1.4 \mathrm{~V}$. In the subsequent $\mathrm{C} 1 \rightarrow \mathrm{D} 2$ cycle, the 


\section{WILEY-VCH}

profiles exhibit multiple plateaus and multiple drops between the plateaus, suggesting $\mathrm{K}$ (de)intercalation in the layered NVO proceeds through multiple steps. The plateaus show a good correlation of voltages between $\mathrm{C} 1$ and $\mathrm{D} 2$, forming three pairs at $3.0 / 2.6 \mathrm{~V}, 3.3 / 3.1 \mathrm{~V}$ and 4.1/3.9 V. The NVO structure contains mixed environments of V-O polyhedral, so the vanadium atoms are not equivalent. Previous work reported that during the intercalation of $\mathrm{Li} / \mathrm{Na}$-ions, the ions either occupy the interlayer or intralayer spacing. ${ }^{[36]}$ It is reasonable to deduce that multiple sites exist in the NVO structure for K-ion to occupy, and the sites are not equivalent because the vanadium atoms are not equivalent. It means the sites are occupied by $\mathrm{K}$-ions in sequence, and the vanadium polyhedral coordination changes in sequence accordingly, thereby causing multiple stages of phase transformation depending on the level of K-ion intercalation. As known, voltage plateau corresponds to a two-phase process while voltage drop corresponds to a single-phase process. ${ }^{[37]}$ The multiple voltage plateaus/drops observed in Figure 3a indicate the multiple phase transformations between single- and twophase process that are dependent on the (de)intercalation level of K-ions (Figure S5). To investigate the electrochemical mechanism, ex-situ XPS measurement was performed after D1, C1 and D2, and the V 2p core level spectra are shown in Figure 3b. Compared with the pristine state, $\mathrm{V}^{4+}$ content increases after $\mathrm{D} 1$, indicating $\mathrm{V}$ is reduced upon $\mathrm{K}$-intercalation. D1 delivers a discharge capacity of $102 \mathrm{mAh} \mathrm{g}^{-1}$ that corresponds to 1.5 mol intercalated $\mathrm{K}^{+}$per molecule. During $\mathrm{C} 1, \mathrm{~V}^{4+}$ content decreases while $\mathrm{V}^{5+}$ content increases upon $\mathrm{K}$ deintercalation. The $\mathrm{C} 1$ capacity is $165 \mathrm{mAh} \mathrm{g}^{-1}$ and corresponds to $2.4 \mathrm{~mol}$ electron transfer. It is important to point out that $\mathrm{N}$ content (relative to $\mathrm{V}$ ) changes from 0.25 (1 mol per molecule) after $\mathrm{D} 1$ to 0.15 ( $0.6 \mathrm{~mol}$ per molecule) after $\mathrm{C} 1$. This suggests $0.4 \mathrm{~mol} \mathrm{NH}_{4}{ }^{+}$deintercalates during the charging process and contributes to the charge capacity. This is verified by the decrease of the peak intensity from the N-H bond in the FTIR spectrum after $\mathrm{C} 1$ (Figure S6). Therefore, extra $0.5 \mathrm{~mol} \mathrm{~V} \mathrm{~V}^{4+}$ is oxidized besides the $1.5 \mathrm{~mol} \mathrm{~V}^{4+}$ that is formed during D1. Deammoniation at high voltage was also observed in Mg-ion storage in 


\section{WILEY-VCH}

layered vanadium oxide. ${ }^{[38]}$ It causes material's structural instability and deteriorates its K-ion storage performance. D2 exhibits more significant increasing of $\mathrm{V}^{4+}$ than D1 and delivers a discharge capacity of $143 \mathrm{mAh} \mathrm{g}^{-1}$, which corresponds to 2 mol K-intercalation, being consistent with the analysis of D1 and $\mathrm{C} 1$. It is noted that $\mathrm{N}$ content remains stable from $\mathrm{C} 1$ onward (0.15 at $\mathrm{C} 1$ and 0.14 at $\mathrm{D} 1)$, showing (de)intercalation of $\mathrm{K}^{+}$is mainly responsible for the K-ion storage after initial cycles. The XPS analysis reveals the critical role of the presence of $\mathrm{NH}_{4}{ }^{+}$in the interlayer space.

The cycling stability of NVO was next examined by a series of electrochemical measurements. Figure 4a shows the cyclic voltammetry (CV) curves of cycle1, 2 and 10 at a scan rate of $0.1 \mathrm{mV} \mathrm{s}^{-1}$. During the first cathodic scan (D1), one sharp peak at $2.5 \mathrm{~V}$ and one broad peak centered at $1.4 \mathrm{~V}$ are observed, which matches well with D1 profile (Figure 3a). During the first anodic scan $(\mathrm{C} 1)$, three peaks are observed, i.e., one at $3.0 \mathrm{~V}$ with a small shoulder $2.7 \mathrm{~V}$, one at $3.3 \mathrm{~V}$, and one extending from $3.9 \mathrm{~V}$ to the cut-off voltage. In cycle2 (D2/C2), three redox pairs can be seen at 3.0/2.6 V (a shoulder pair at 2.7/2.5 V), 3.3/3.0 V, and 4.2/3.9 V. The voltages are in good agreement with the plateaus shown in Figure 3a, demonstrating the multi-step K-intercalation in NVO. A substantial irreversible current loss after first two cycles occurs at 3.9-4.2 V, which is attributed to the deammoniation in this voltage region. Figure $\mathbf{4 b}$ shows the cycling performance in the range of 1-4.2 V, where the discharge capacity rapidly decreases to $41 \mathrm{mAh} \mathrm{g}^{-1}$ after 30 cycles. XRD patterns were recorded after D1, C1, D2 and C2 to investigate the structural stability of NVO (Figure 4c). Careful observations disclose two changes of the patterns, i.e., shifting of the (001) peak and remaining of the intercalated intermediate. First, the (001) peak shifts from $8.7^{\circ}$ at the pristine state to $9.8^{\circ}$ after D1, which indicates shrinkage of the interlayer spacing upon $\mathrm{K}$ intercalation. This is attributed to the increased interaction between $\mathrm{K}^{+}$and negatively charged $\mathrm{V}-\mathrm{O}$ units and the reduced electrostatic repulsion between the $\mathrm{O}^{2-}$ in the neighboring layers. Same phenomenon was reported for Na- and K-intercalation in layered materials. ${ }^{[28,39]}$ The 


\section{WILEY-VCH}

peak shifts back to $9.3^{\circ}$ after $\mathrm{C} 1$ and shuttles between $9.8^{\circ}$ and $9.3^{\circ}$ in the $\mathrm{D} 2 / \mathrm{C} 2$ cycle (inset in Figure 4c). This suggests the layered structure is preserved but partial intercalated $\mathrm{K}^{+}$are trapped between the layers, causing cycling irreversibility. Second, the pattern changes after D1 and recovers after C1. Although the pattern after D1 (marked by \#) cannot be indexed to the existing vanadium bronzes, we speculate the intercalated intermediate is $\mathrm{K}^{+} / \mathrm{NH}_{4}{ }^{+}$bication intercalated vanadium bronze, based on our XPS results (Figure 3b) and previous reports of $\mathrm{Na}^{+} / \mathrm{NH}_{4}{ }^{+}$bi-cation intercalated vanadium oxides. ${ }^{[40,41]}$ The intermediate appears again after D2 and remains detectable after C2, which suggests incomplete K-deintercalation, being consistent with the K-trapping pointed out in the first point. Electrochemical impedance spectroscopy (EIS) measurement was performed to further evaluate NVO's structural stability. The equivalent circuit is shown in Figure S7 and the fitted resistances are summarized in Table S1. As shown in Figure 4d, the radius of the semicircles significant increases from cycle 2 to cycle 15 , resembling the capacity decay in the initial 20 cycles. This signals a cycling induced increase in the charge transfer resistance $\left(R_{c t}\right) . R_{c t}$ increases from $961 \Omega$ at cycle 2 to $3702 \Omega$ at cycle15 and further to $4830 \Omega$ at cycle 50 . It is associated with the progressive collapse of the layered structure, which could increase the NVO/electrolyte interface with prolonging cycles. ${ }^{[42,43]}$ As seen in the SEM image after 50 cycles (Figure S8), the flower-like architecture collapses, and the nanowires can hardly be identified, visually demonstrating the deterioration of the layered structure. The observations are in sharp contrast with those of the electrode before cycling, as shown in Figure S9. Combining the XPS, XRD, EIS and SEM analysis, it can be concluded that deammoniation and $\mathrm{K}^{+}$trapping cause the instability of the layered structure and the rapid deterioration of the K-ion storage performance.

Based on the above analysis, voltage window is controlled to refine the cycling stability. NVO was cycled in three windows of 2-4.2, 1-3.8 and 2-3.8 V, and the results are shown in

Figure 5. CV curves (Figure 5a) exhibit similar features in all three windows, and the redox 


\section{WILEY-VCH}

pairs in each window are in reasonable agreement with those observed in Figure 4a. The curves exhibit better overlapping in $1 / 2-3.8 \mathrm{~V}$ than in $2-4.2 \mathrm{~V}$, which is associated with the reduced deammoniation towards the cut-off voltage. Peak current increases at cycle10 in 1/23.8 V, also indicating the better cycling stability in the two windows. Charge/discharge profiles are shown in Figure $\mathbf{5 b}$ and capacities and CEs are summarized in Table S2. Although the highest initial charge capacity of $210 \mathrm{mAh} \mathrm{g}^{-1}$ is delivered in 2-4.2 $\mathrm{V}$, it rapidly decays to $114 \mathrm{mAh} \mathrm{g}^{-1}$ at cycle10. In contrast, initial capacities of 106 and $86 \mathrm{mAh} \mathrm{g}^{-1}$ are delivered in 1-3.8 and 2-3.8 V, respectively, and they remain stable at cycle10. Thus, CEs are higher in 1/2-3.8 $\mathrm{V}$ than 2-4.2 $\mathrm{V}$, being in accordance with the better overlapping of the $\mathrm{CV}$ curves. This result indicates that keeping $\mathrm{NH}_{4}{ }^{+}$in the interlayer space of $\mathrm{NVO}$ could be crucial for the cycling performance with a sacrifice of initial capacity but much enhanced capacity retention. XRD patterns after C2 are shown in Figure S10. The pattern in 2-3.8 V fully recovers to NVO, whereas the one in $2-4.2 \mathrm{~V}$ shows peaks of the intercalated intermediate. EIS results further demonstrate the better cycling stability in 1/2-3.8 V (Figure 5c). Compared to $2-4.2 \mathrm{~V}$, the radius of the semicircles shows a much smaller increase in 13.8 $\mathrm{V}$ and for the case of 2-3.8 V, they remain almost unchanged over the cycles. As can be seen in Table S1, $R_{c t}$ increases from $2832 \Omega$ at cycle 2 to $4728 \Omega$ at cycle50 in $2-4.2 \mathrm{~V}$, being comparable to those in 1-4.2 and thus indicating the structural instability. However, the $R_{c t}$ is much smaller in $1 / 2-3.8 \mathrm{~V}$, where it increases from 1458 to $2898 \Omega$ in $1-3.8 \mathrm{~V}$ and from 1030 to $1295 \Omega$ in $2-3.8 \mathrm{~V}$. The comparison of $R_{c t}$ is in accordance with the capacity decay observed in different voltage windows. It is worth mentioning that the cycling stability of NVO at a low rate is mainly dependent on the change of $R_{c t}$ rather than the formation of solidelectrolyte interface ( $R_{\text {int }}$ in Table S1), although higher $R_{\text {int }}$ is observed when discharging NVO to $1 \mathrm{~V}$ than $2 \mathrm{~V}$. The EIS analysis suggests the layered structure is kept intact when lowering the cut-off voltage to $3.8 \mathrm{~V}$. As expected, after 50 cycles in 2-3.8 V, the flower-like architecture of NVO is preserved and nanowires can be clearly identified (Figure S11). The 


\section{WILEY-VCH}

observations are in a sharp contrast with those in Figure S8 and in agreement with those in Figure S9. With the voltage window refined to 1/2-3.8 V, NVO exhibits not only high plateau voltages but also small polarization. The charge/discharge separation is comparable to P2/P3type layered metal oxides and even smaller than PBA cathodes. ${ }^{[13,14,19,20]}$

The KIB performance of NVO in the refined voltage windows is fully demonstrated by long-term stability and great rate capability. Figure 6a shows the cycling performance at 50 $\mathrm{mA} \mathrm{g}^{-1}$ for 200 cycles. NVO delivers a cycle 2 discharge capacity of $116 \mathrm{mAh} \mathrm{g}^{-1}$ in 1-3.8 V. The discharge capacity reaches the highest of $136 \mathrm{mAh} \mathrm{g}^{-1}$ in the middle stage of cycling and retains $109 \mathrm{mAh} \mathrm{g}^{-1}$ at cycle200, which is $96 \%$ of the cycle 2 capacity and results in a very small decay rate of $0.02 \%$ per cycle. The long-term stability also sustains in $2-3.8 \mathrm{~V}$. NVO delivers the discharge capacities of 80 and $75 \mathrm{mAh} \mathrm{g}^{-1}$ at cycle 2 and cycle200, respectively, exhibiting a flat cycling curve and a decay rate of $0.03 \%$ per cycle. Previously reported vanadium oxide KIB cathodes exhibit capacity retention less than $80 \%$ within 100 cycles. ${ }^{[27,28,44]}$ In contrast, the presented long-term stability over 200 cycles far surpasses the previous vanadium oxide KIB cathodes and to the best of our knowledge, is among the best in all the reported KIB cathodes. ${ }^{[20,45,46]}$ Figure $\mathbf{6 b}$ displays the rate capability at the range of 0.05-3 $\mathrm{A} \mathrm{g}^{-1}$. In 1-3.8 V, NVO exhibits high capacities of 108 and $73 \mathrm{mAh} \mathrm{g}^{-1}$ at 0.05 and 0.1 $\mathrm{A} \mathrm{g}^{-1}$, respectively. Even though the capacity decreases quickly with increasing the rate, 43 and $35 \mathrm{mAh} \mathrm{g}^{-1}$ are retained at 0.5 and $1 \mathrm{~A} \mathrm{~g} \mathrm{~g}^{-1}$, respectively, which is better than the previously reported $\mathrm{K}_{0.5} \mathrm{~V}_{2} \mathrm{O}_{5}{ }^{[28]}$ and $\mathrm{V}_{2} \mathrm{O}_{5} \cdot 0.6 \mathrm{H}_{2} \mathrm{O}$ cathode. ${ }^{[44]}$ Strikingly, NVO exhibits even better rate capability in 2-3.8 V. It delivers stable capacities at all testing rates, retaining 57 $\mathrm{mAh} \mathrm{g}^{-1}$ at $0.1 \mathrm{~A} \mathrm{~g}^{-1}$ and $51 \mathrm{mAh} \mathrm{g}^{-1}$ at a rate as high as $3 \mathrm{~A} \mathrm{~g}^{-1}$. This means $90 \%$ capacity is retained when the rate increases by 30 times. A $100 \%$ recovery is obtained when the rate is reduced back to $0.05 \mathrm{~A} \mathrm{~g}^{-1}$. The charge/discharge profiles at different rates are shown in Figure S12. Moreover, long-term stability at high rates was also tested in 2-3.8 V. As shown in Figure 6c, NVO delivers capacities of 52, 48 and $47 \mathrm{mAh} \mathrm{g}^{-1}$ after 200 cycles at 0.5, 1 and 


\section{WILEY-VCH}

$3 \mathrm{~A} \mathrm{~g} \mathrm{~g}^{-1}$, respectively. The capacity retention is higher than $90 \%$ at all three rates. It is important to emphasize that the reported KIB cathodes have rarely been tested at a rate higher than $1 \mathrm{~A} \mathrm{~g} \mathrm{~g}^{-1}$ and only very few of P3-type layered metal oxides have been able to deliver stable capacities at high rates $\left(\leq 1 \mathrm{~A} \mathrm{~g}^{-1}\right)$ over prolonged cycles. ${ }^{[23,47]} \mathrm{NVO}$ reported in this work not only sustains at the high rates well beyond $1 \mathrm{~A} \mathrm{~g}^{-1}$ but also exhibits high capacity retention at these high rates. Therefore, the great rate capability and high long-term stability at both low and high rates full demonstrate the promise of NVO as a KIB cathode.

\section{Conclusion}

In summary, ammonium vanadium bronze is investigated as a cathode material in KIBs for the first time. The as-synthesized NVO features a large interlayer spacing of $9.8 \AA$ and selfassembled flower-like architecture. It delivers capacities of 136 and $75 \mathrm{mAh} \mathrm{g}^{-1}$ at $50 \mathrm{~mA} \mathrm{~g}^{-1}$ in the voltage windows of 1-3.8 $\mathrm{V}$ and 2-3.8 V, respectively. It shows great cycling stability at both low $\left(50 \mathrm{~mA} \mathrm{~g}^{-1}\right)$ and high rates $\left(3 \mathrm{~A} \mathrm{~g}^{-1}\right)$ for 200 cycles. Especially, it exhibits fast rate capability by retaining $90 \%$ capacity $\left(51 \mathrm{mAh} \mathrm{g}^{-1}\right)$ at $3 \mathrm{~A} \mathrm{~g}^{-1}$ in the voltage window of 2-3.8 $\mathrm{V}$. A study of electrochemical mechanism suggests that the (de)intercalation of $\mathrm{K}^{+}$is a topotactic process, where transition between $\mathrm{V}^{4+}$ and $\mathrm{V}^{5+}$ occurs. It also shows prevention of deammoniation at high voltage is critical to enhance the structural stability of NVO, which is realized by controlling voltage window to refine the $\mathrm{K}$-ion storage performance. We hope this work can stimulate future exploitation of vanadium oxides in KIBs and more insights into mechanisms of K-ion storage.

\section{Experimental Section}

Materials synthesis: NVO was synthesized using a hydrothermal method. In a typical procedure, $2.74 \mathrm{mmol} \mathrm{NH}_{4} \mathrm{VO}_{3}$ and $4.6 \mathrm{mmol} \mathrm{H}_{2} \mathrm{C}_{2} \mathrm{O}_{4} \cdot 2 \mathrm{H}_{2} \mathrm{O}$ were added in $40 \mathrm{ml}$ DI water under stirring. The mixture was kept stirring for $0.5 \mathrm{~h}$ and then transferred to a Teflon-lined 


\section{WILEY-VCH}

stainless-steel autoclave. The autoclave was sealed and maintained at $180^{\circ} \mathrm{C}$ for $3 \mathrm{~h}$. After cooling to room temperature naturally, the product was collected by centrifuging the mixture, rinsed with absolute ethanol several times, and then dried in vacuum at $60^{\circ} \mathrm{C}$.

Characterizations: XRD analysis was performed on an $18 \mathrm{KW}$ D/MAX2500V PC diffractometer using $\mathrm{Cu} \mathrm{K \alpha}(\lambda=1.54 \AA)$ radiation at a scanning rate of $2^{\circ} \mathrm{min}^{-1}$. SEM analysis was conducted using a JEOL JSM-7500F electron scanning microscopy. TEM analysis was performed on a JEOL 2100F transmission electron microscope. X-ray photoelectron spectra were acquired on an ESCALAB 250Xi with $\mathrm{Mg} \mathrm{K \alpha}(h v=1253.6 \mathrm{eV})$ as the excitation source. The binding energies obtained in the XPS spectra analysis were corrected for specimen charging by referencing $\mathrm{C}$ 1s to $284.8 \mathrm{eV}$. Raman spectrum was recorded at room temperature with an inVia Raman microscope. Fourier transform infrared spectrum was recorded with a Thermo Nicolet AVATAR 370 DTGS. TG analysis was conducted using a NETZSCH STA 409 PG/PC instrument.

Electrochemical measurements: The electrodes were fabricated by mixing NVO, Super P and poly(vinylidenedifluoride) (PVDF) at a weight ratio of 70:20:10, then coated uniformly (doctor-blade) on an aluminum foil with a mass loading of $1.0-2.0 \mathrm{mg} \mathrm{cm}^{-2}$. The electrodes were dried at $110^{\circ} \mathrm{C}$ under vacuum for more than $12 \mathrm{~h}$. Electrochemical tests were carried out using coin cells, CR2032, which were assembled in an Ar-filled glovebox with oxygen and moisture concentrations kept below $0.1 \mathrm{ppm}$. $\mathrm{K}$ foil used as counter electrode was separated from working electrode by a glass microfiber filter (Whatman, Grade GF/B). The electrolyte was $0.8 \mathrm{M} \mathrm{KFP}_{6}$ in an ethylene carbonate (EC)/propylene carbonate (PC) solution (1:1). Cyclic voltammetry and electrochemical impedance spectroscopy measurements were performed on a VSP electrochemical workstation (Bio-Logic, France). Galvanostatic charge/discharge was performed on a Land CT 2001A battery testing system (Land, China) at room temperature. 


\section{Supporting Information}

Supporting Information is available from the Wiley Online Library or from the author.

\section{Acknowledgements}

This work was supported by the European Research Council (ThreeDsurface, 240144 and HiNaPc, 737616), BMBF (ZIK-3DNanoDevice, 03Z1MN11), and German Research Foundation (DFG: LE2249/4-1 and LE2249/5-1).

Received: ((will be filled in by the editorial staff))

Revised: ((will be filled in by the editorial staff)) Published online: ((will be filled in by the editorial staff))

References

[1] H. Kim, J. C. Kim, M. Bianchini, D. H. Seo, J. Rodriguez-Garcia, G. Ceder, Adv. Energy Mater. 2018, 8, 1702384.

[2] J. C. Pramudita, D. Sehrawat, D. Goonetilleke, N. Sharma, Adv. Energy Mater. 2017, 7, 1602911.

[3] S. Komaba, T. Hasegawa, M. Dahbi, K. Kubota, Electrochem. Commun. 2015, 60, 172.

[4] M. Okoshi, Y. Yamada, S. Komaba, A. Yamada, H. Nakai, J. Electrochem. Soc. 2017, 164, A54.

[5] J. Zhao, X. Zou, Y. Zhu, Y. Xu, C. Wang, Adv. Funct. Mater. 2016, 26, 8103.

[6] W. Wang, J. Zhou, Z. Wang, L. Zhao, P. Li, Y. Yang, C. Yang, H. Huang, S. Guo, Adv. Energy Mater. 2018, 8, 1701648.

[7] Y. Xu, C. Zhang, M. Zhou, Q. Fu, C. Zhao, M. Wu, Y. Lei, Nature Commun. 2018, 9, 1720.

[8] Q. Zhang, J. Mao, W. K. Pang, T. Zheng, V. Sencadas, Y. Chen, Y. Liu, Z. Guo, Adv. Energy Mater. 2018, 8, 1703288.

[9] I. Sultana, M. M. Rahman, T. Ramireddy, Y. Chen, A. M. Glushenkov, J. Mater. Chem. A 2017, 5, 23506. 


\section{WILEY-VCH}

[10] C. Yang, J. Feng, F. Lv, J. Zhou, C. Lin, K. Wang, Y. Zhang, Y. Yang, W. Wang, J. Li, Adv. Mater. 2018, 1800036.

[11] J. Zhou, L. Wang, M. Yang, J. Wu, F. Chen, W. Huang, N. Han, H. Ye, F. Zhao, Y. Li, Adv. Mater. 2017, 1702061.

[12] W. Zhang, J. Mao, S. Li, Z. Chen, Z. Guo, J. Am. Chem. Soc. 2017, 139, 3316.

[13] C. Zhang, Y. Xu, M. Zhou, L. Liang, H. Dong, M. Wu, Y. Yang, Y. Lei, Adv. Funct. Mater. 2017, 1604307..

[14] L. Xue, Y. Li, H. Gao, W. Zhou, X. Lü, W. Kaveevivitchai, A. Manthiram, J. B. Goodenough, J. Am. Chem. Soc. 2017, 139, 2164.

[15] X. Wu, Z. Jian, Z. Li, X. Ji, Electrochem. Commun. 2017, 77, 54.

[16] J. Han, G.-N. Li, F. Liu, M. Wang, Y. Zhang, L. Hu, C. Dai, M. Xu, Chem. Commun. 2017, 53, 1805.

[17] K. Chihara, A. Katogi, K. Kubota, S. Komaba, Chem. Commun. 2017, 53, 5208.

[18] W. B. Park, S. C. Han, C. Park, S. U. Hong, U. Han, S. P. Singh, Y. H. Jung, D. Ahn, K. S. Sohn, M. Pyo, Adv. Energy Mater. 2018, 8, 1703099.

[19] Y. Hironaka, K. Kubota, S. Komaba, Chem. Commun. 2017, 53, 3693.

[20] J.-Y. Hwang, J. Kim, T.-Y. Yu, S.-T. Myung, Y.-K. Sun, Energy Environ. Sci. 2018, DOI: $10.1039 / C 8 E E 01365 A$.

[21] C. Vaalma, G. A. Giffin, D. Buchholz, S. Passerini, J. Electrochem. Soc. 2016, 163, A1295.

[22] N. Yabuuchi, M. Kajiyama, J. Iwatate, H. Nishikawa, S. Hitomi, R. Okuyama, R. Usui, Y. Yamada, S. Komaba, Nat. Mater. 2012, 11, 512.

[23] X. Wang, X. Xu, C. Niu, J. Meng, M. Huang, X. Liu, Z. Liu, L. Mai, Nano Lett. 2017, $17,544$.

[24] Y. Wang, G. Cao, Chem. Mater. 2006, 18, 2787. 


\section{WILEY-VCH}

[25] N. A. Chernova, M. Roppolo, A. C. Dillon, M. S. Whittingham, J. Mater. Chem. 2009, $19,2526$.

[26] L. Wen, Z. Wang, Y. Mi, R. Xu, S. Yu, Y. Lei, Small 2015, 11, 3408.

[27] M. Clites, J. L. Hart, M. L. Taheri, E. Pomerantseva, ACS Energy Lett. 2018, 3, 562.

[28] L. Deng, X. Niu, G. Ma, Z. Yang, L. Zeng, Y. Zhu, L. Guo, Adv. Funct. Mater. 2018, 1800670.

[29] D. Fang, L. Li, W. Xu, G. Li, Z. Luo, C. Liang, Y. Ji, J. Xu, C. Xiong, RSC Adv. 2014, 4, 25205.

[30] E. Andrukaitis, P. Jacobs, J. Lorimer, Solid State Ionics 1990, 37, 157.

[31] D. Fang, Y. Cao, R. Liu, W. Xu, S. Liu, Z. Luo, C. Liang, X. Liu, C. Xiong, Appl. Surf. Sci. 2016, 360, 658.

[32] X. Wu, Y. Tao, L. Dong, J. Hong, J. Mater. Chem. 2004, 14, 901.

[33] S. Sarkar, P. Veluri, S. Mitra, Electrochim. Acta 2014, 132, 448.

[34] Y. Xu, X. Han, L. Zheng, W. Yan, Y. Xie, J. Mater. Chem. 2011, 21, 14466.

[35] Y. Xu, X. Han, L. Zheng, S. Wei, Y. Xie, Dalton Trans. 2011, 40, 10751.

[36] T. Sarkar, P. Kumar, M. D. Bharadwaj, U. Waghmare, Phys. Chem. Chem. Phys. 2016, $18,9344$.

[37] D. Li, H. Zhou, Mater. Today 2014, 17, 451.

[38] E. A. Esparcia, M. S. Chae, J. D. Ocon, S.-T. Hong, Chem. Mater. 2018, 30, 3690.

[39] K. Zhu, C. Zhang, S. Guo, H. Yu, K. Liao, G. Chen, Y. Wei, H. Zhou, ChemElectroChem 2015, 2, 1660.

[40] H.-L. Fei, Z.-R. Shen, J.-G. Wang, H.-J. Zhou, D.-T. Ding, T.-H. Chen, Electrochem. Commun. 2008, 10, 1541.

[41] H. Fei, Z. Shen, J. Wang, H. Zhou, D. Ding, T. Chen, J. Power Sources 2009, 189, 1164 


\section{WILEY-VCH}

[42] Y. Xu, E. M. Lotfabad, H. Wang, B. Farbod, Z. Xu, A. Kohandehghan, D. Mitlin, Chem. Commun. 2013, 49, 8973.

[43] M. Zhou, Y. Xu, C. Wang, Q. Li, J. Xiang, L. Liang, H. Zhao, M. Wu, Y. Lei, Nano Energy 2017, 31, 514.

[44] B. Tian, W. Tang, C. Su, Y. Li, ACS Appl. Mater. Interfaces 2017, 10, 642.

[45] G. He, L. F. Nazar, ACS Energy Lett. 2017, 2, 1122.

[46] T. Deng, X. Fan, C. Luo, J. Chen, L. Chen, S. Hou, N. Eidson, X. Zhou, C. Wang, Nano Lett. 2018, 18, 1522.

[47] N. Naveen, W. B. Park, S. C. Han, S. P. Singh, Y. H. Jung, D. Ahn, K.-S. Sohn, M. Pyo, Chem. Mater. 2018, 30, 2049.
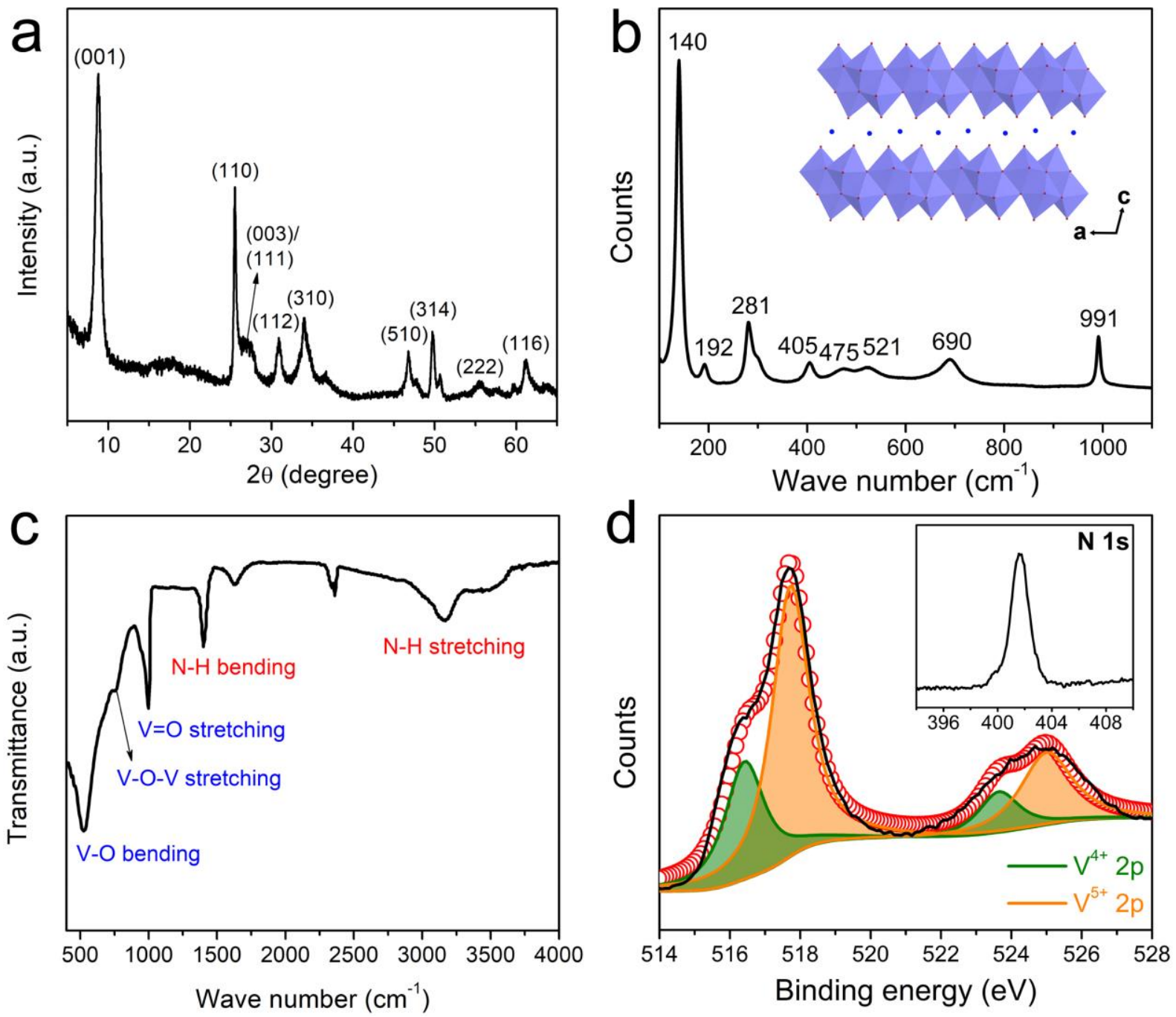


\section{WILEY-VCH}

Figure 1. XRD pattern (a), Raman spectrum (b), FTIR spectrum (c), and V 2p core level XPS spectrum (d) of NVO. Inset in (b) is the crystal structure of NVO along the $b$-axis. Red and Blue balls represent $\mathrm{O}$ and $\mathrm{NH}_{4}{ }^{+}$. Inset in (d) is $\mathrm{N} 1$ s core level XPS spectrum.
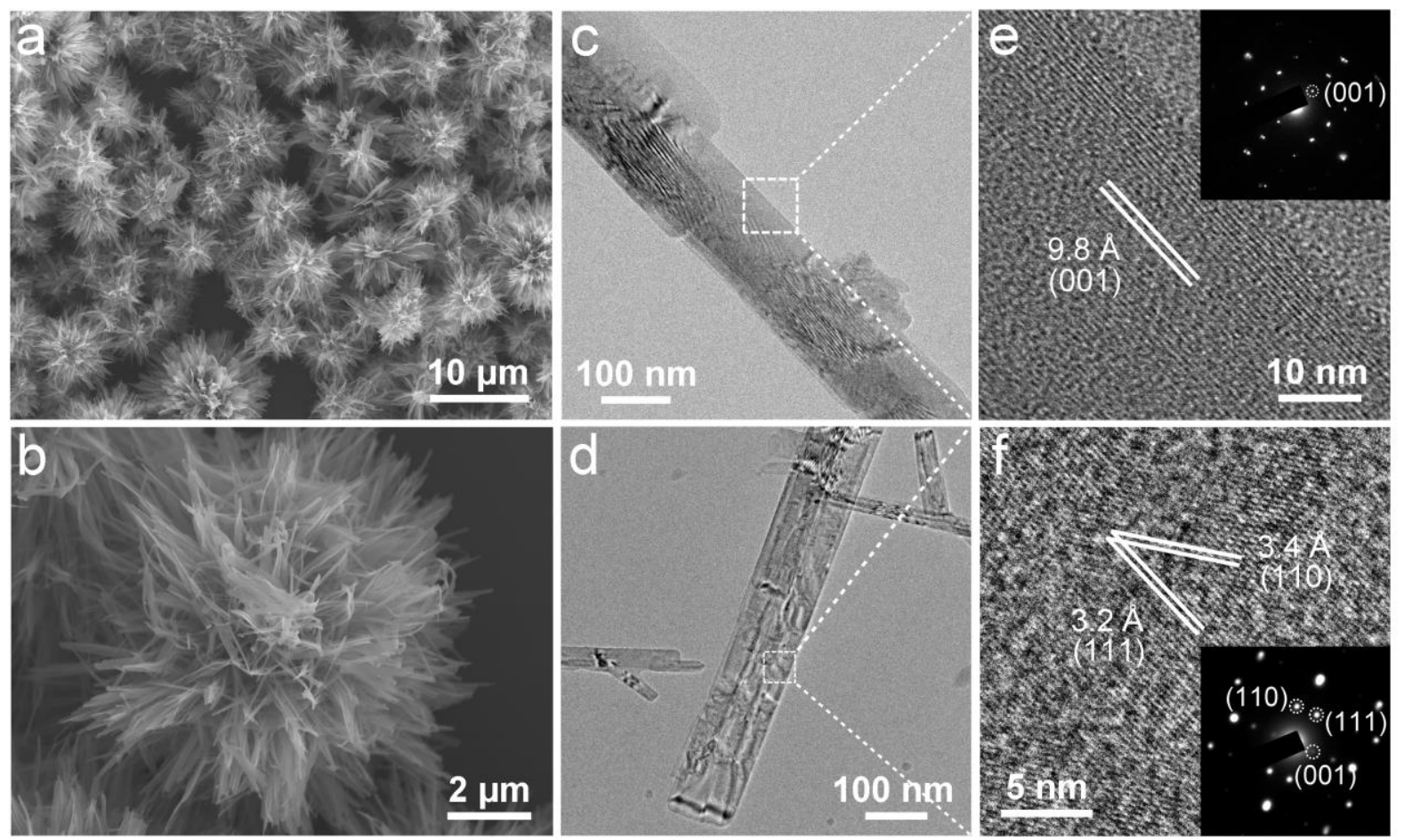

Figure 2. ( $a$ and b) SEM images of the NVO "flowers". TEM (c and d) and HRTEM images (e and f) of individual nanowires. Insets in (e) and (f) are SAED patterns.
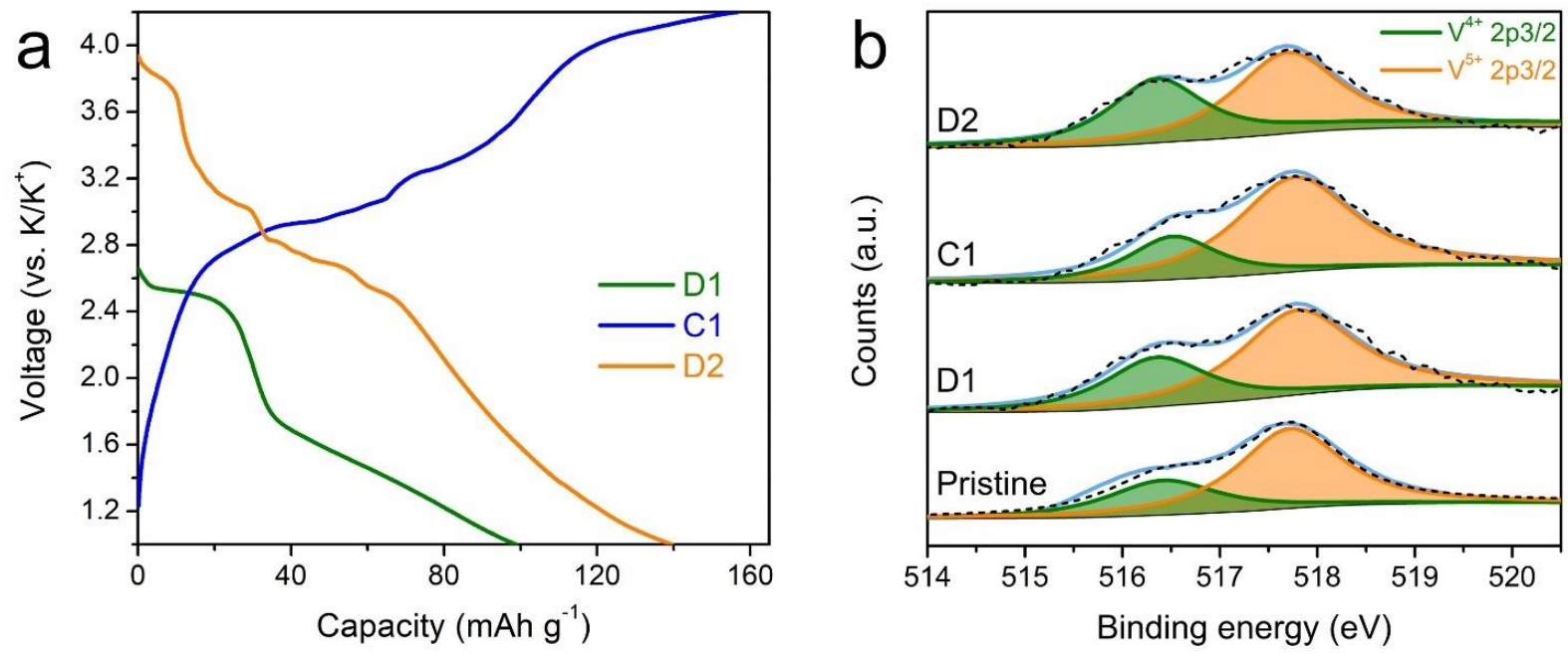

Figure 3. Charge/discharge profiles (a) and V 2p core level XPS spectra (b) after D1, C1 and D2. 
WILEY-VCH
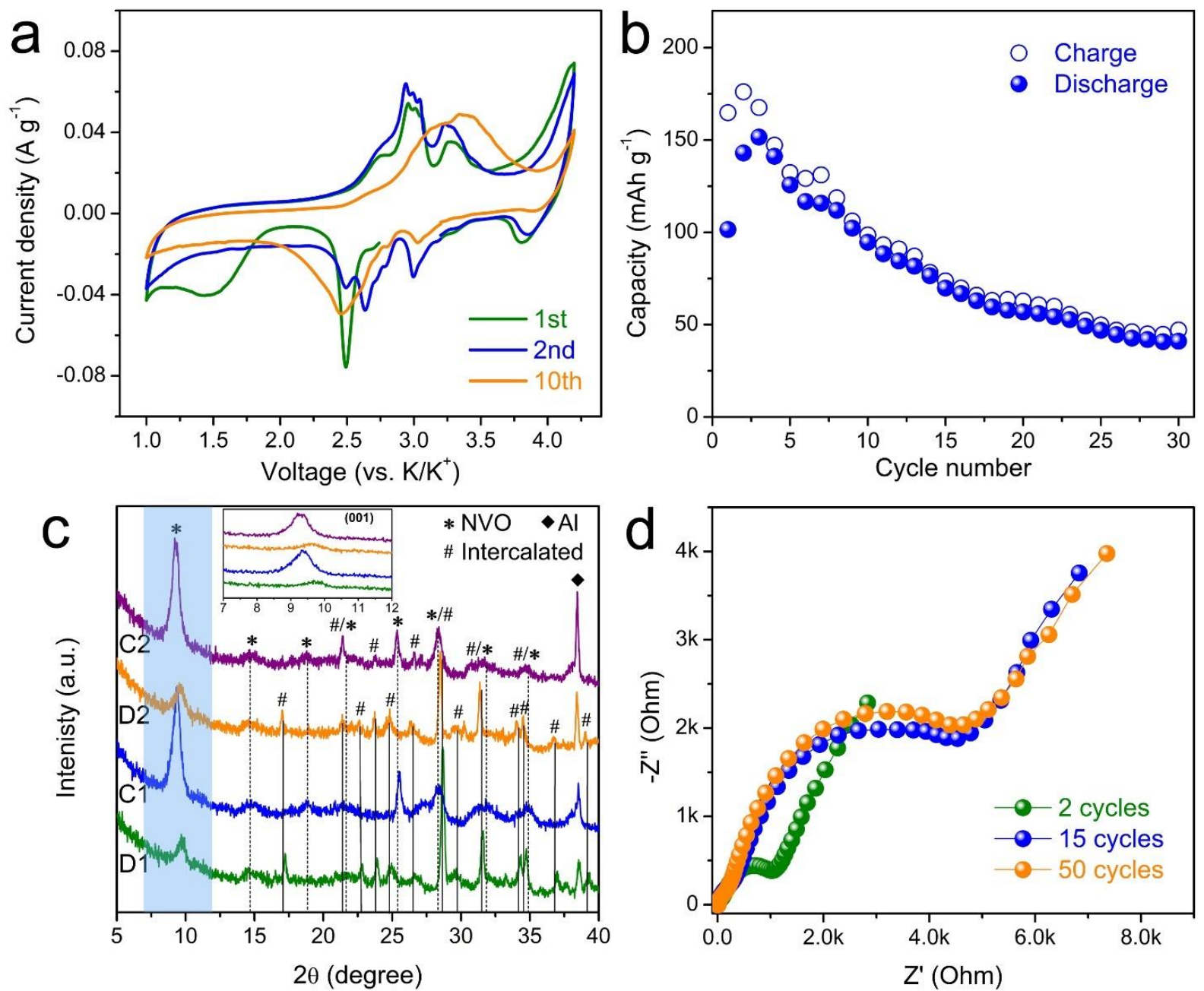

Figure 4. (a) CV curves of NVO after 1, 2 and 10 cycles at a scan rate of $0.1 \mathrm{mV} \mathrm{s}^{-1}$. (b) Cycling performance at $50 \mathrm{~mA} \mathrm{~g}^{-1}$. (c) XRD patterns after D1, C1, D2 and C2. (d) EIS spectra after 2, 15 and 50 cycles. 
WILEY-VCH
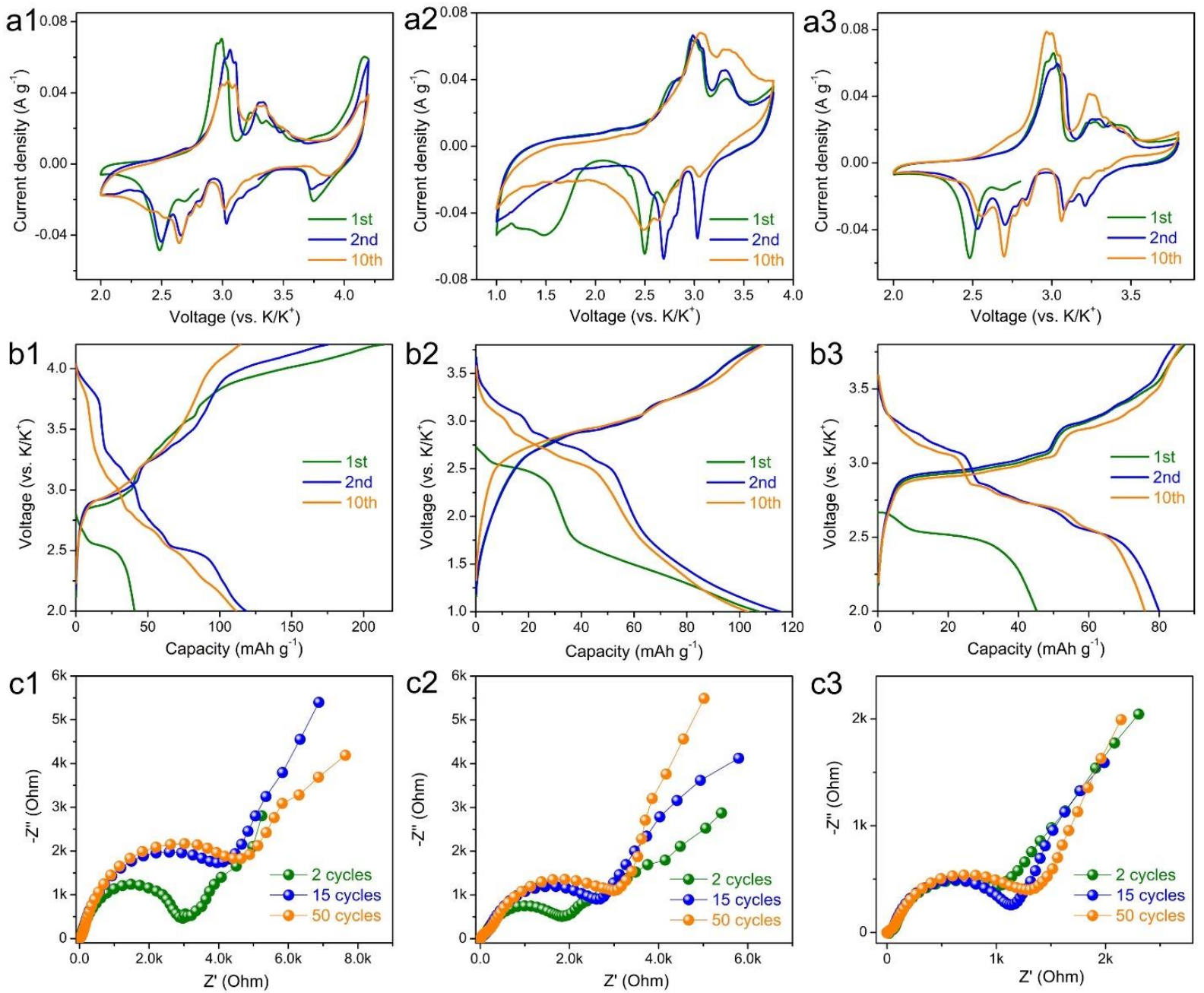

Figure 5. (a) $\mathrm{CV}$ curves after 1,2 and 10 cycles at a scan rate of $0.1 \mathrm{mV} \mathrm{s}^{-1}$, (b) the corresponding charge/discharge profiles at $50 \mathrm{~mA} \mathrm{~g}^{-1}$, and (c) EIS spectra after 2, 15 and 50 cycles of NVO in the voltage window of (1) $2-4.2 \mathrm{~V}$, (2) $1-3.8 \mathrm{~V}$ and (3) $2-3.8 \mathrm{~V}$. 


\section{WILEY-VCH}
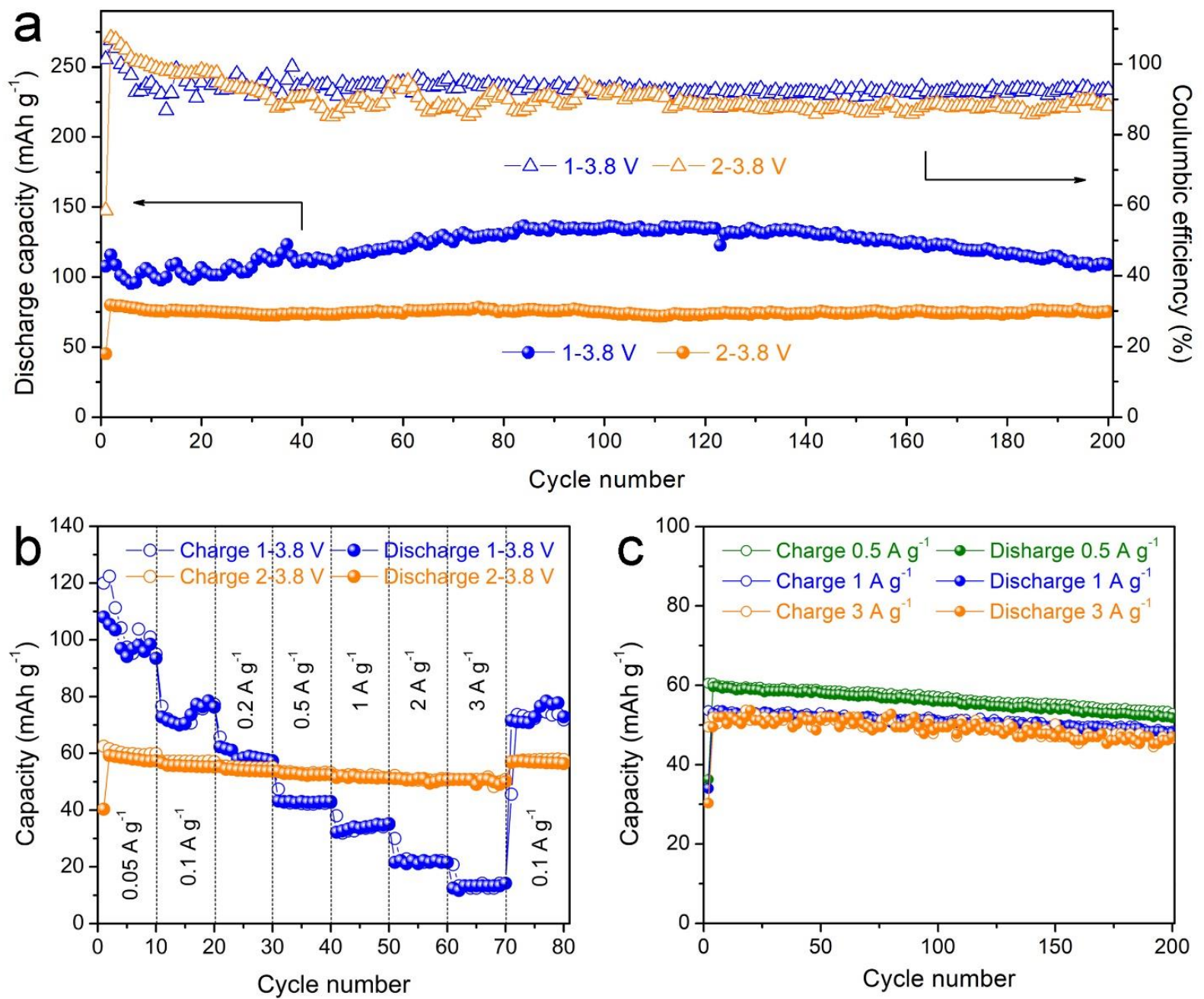

Figure 6. (a) Cycling performance of NVO at $50 \mathrm{~mA} \mathrm{~g}^{-1}$ in $1 / 2-3.8 \mathrm{~V}$. (b) Rate capability of $\mathrm{NVO}$ in the range of $50 \mathrm{~mA} \mathrm{~g}^{-1}$ to $3 \mathrm{~A} \mathrm{~g}^{-1}$ in $1 / 2-3.8 \mathrm{~V}$. (c) Cycling performance of $\mathrm{NVO}$ at high rates in 2-3.8 V. 